\title{
Vacuum Design for the Disk-and-Washer Accelerator Structure
}

\author{
James R. Ruhe \\ Lash D. Hansborough
}
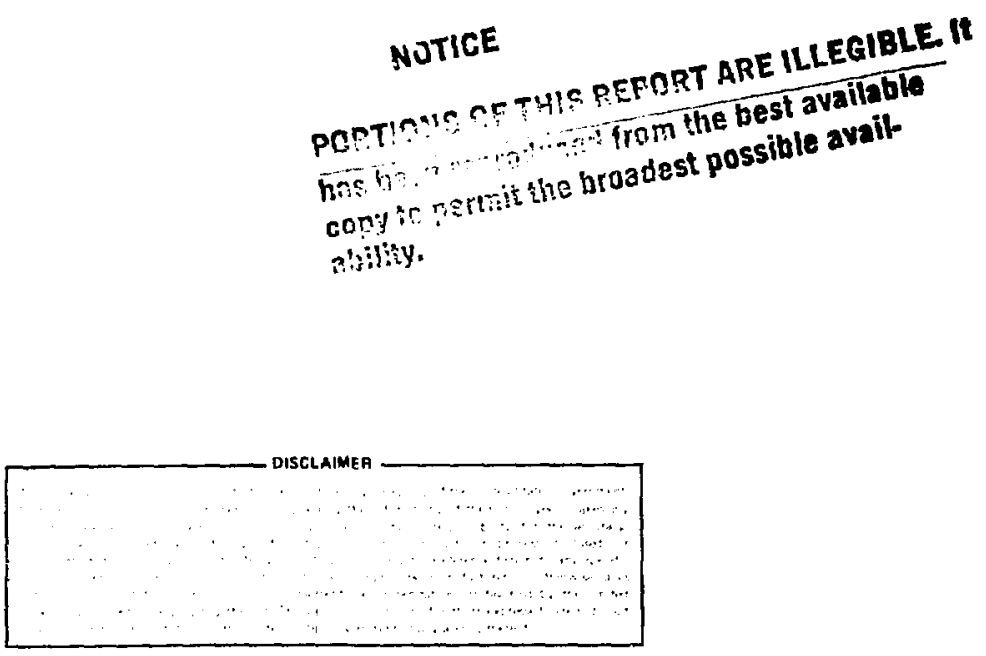

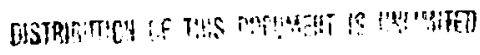<smiles>CCC[Te]</smiles> 
VACUUM DESIGN FOR THE DISK-AND-WASHER

ACCELERATOR STRUCTURE

by

James R. Ruhe and Lash D. Hansborough

ABSTRACT

The disk-and-washer (DAW) accelerator structure is being developed for several applications. Because of its complicated geometry and newness, vacuum calculations for the DAW accelerator structure are not yet formalized. The applicable vacuum equations for this structure are presented and correlations for it have been made with the vacuum data from the Clinton $P$. Anderson Meson Physics Facility side-coupled accelerator structure. A calculation is presented for the DAW structure proposed for the Pion Generator for Medical Irradiations (PIGMI) accelerator.

\section{INTROOUCTION}

Significant discoveries made at Los Alamos during the development of the Clinton P. Anderson Meson Physics Facility (LAMPF) led the way to development of practical structures for acceleration of protons in excess of $200 \mathrm{MeV}$. The structure developed for LAMPF is called the side-coupled structure. The sidecoupled structure (Fig. I) also has been used successfully for the acceleration of electrons in many applications.

The USSR, in their interest in building a LAMPF-type machine, considered using the side-coupled structure, but they selected a disk-and-washer (DAW) structure (Fig. 2) because of its large intercavity coupling and potential for simple fabrication. The initial United States interest in the DAW structure was for the high-energy coupled-cavity linac (CCL) portion of the Pion Generator for Medical Irradiations (PIGMI) accelerator. Much of the experimental 


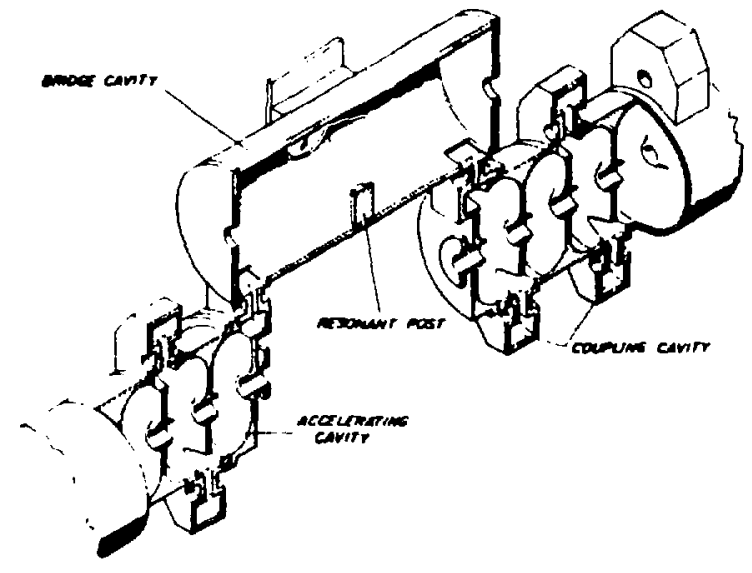

Fig. 1.

LAMPF side-coupled accelerator structure.

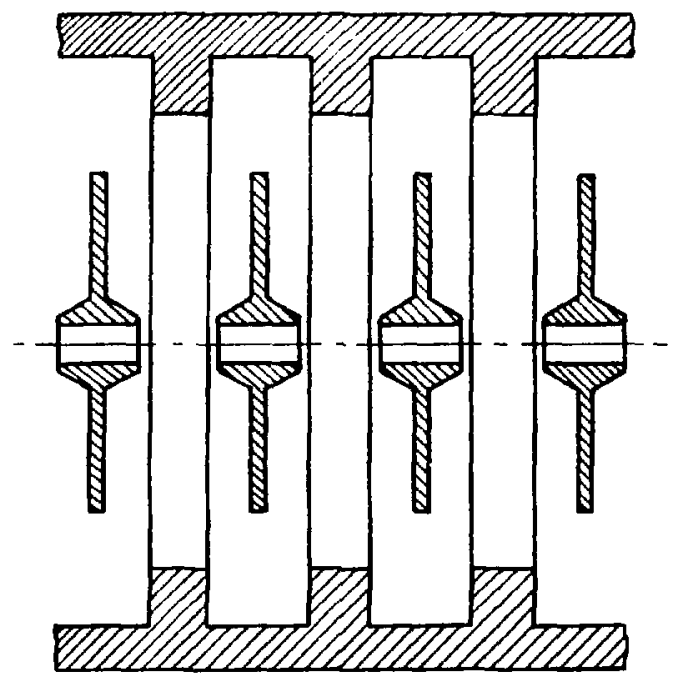

Fig. 2.

Disk-and-washer accelerator structure. (cold-cavity) work has been aimed at determining the optimum washersupport method. ' The cold-cavity experiments have shown that the size and the number of stems should be minimized to avoid distortion of the magnetic fields. Several schemes (Fig. 3) were investigated, and the "tee-stem" approach generally has been adopted.

The 1320-MHz PIGMI DAW structure $^{2}$ is shown in Fig. 4. The accelerating tanks (two are shown) are separated by a coaxial bridge coupler. A portion of the PIGMI CCL is shown in Fig. 5 ; it would have an $234-\mathrm{cm}$ i.d. and would accelerate a 100-uA proton beam from $125 \mathrm{MeV}$ to $650 \mathrm{MeV}$ in $2.99 \mathrm{~m}$. As shown in Fig. 6, the coaxial bridge couplers have a vacuum geometry similar to the DAW structure in the accelerating tanks shown in Fig. 7.

A $2380-\mathrm{MHz}$ continuous-wave (CW), $R=1$ (where $a=$ the speed of light) DAW structure is being fabricated by Los Alamos for an electron accelerator (the racetrack microtron, or RTM) to be installed at the National Bureau of Standards in Washington, DC. ${ }^{3}$ Figures 8 and 9 show some of the RTM DAW structure. The cavity has a $19.6-\mathrm{cm}$ i.d., the disk has a 16.9-cm i.d., and the washer has a 10.4-cm 0.d.; the accelerating cavity is $28 \mathrm{~m}$ long. To raise the 


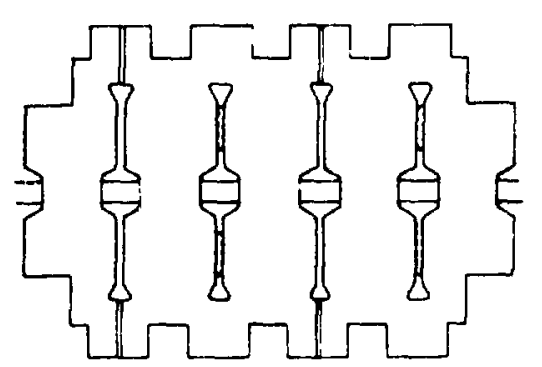

(a) Four radial supports pez washer rotated by $45^{\circ}$ from washer to washer.

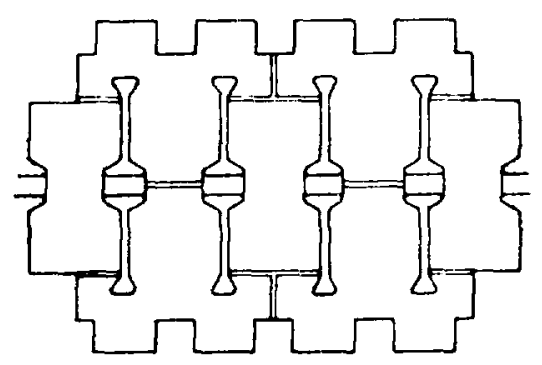

(c) Two T-shaped supports between each washer that are rotated by $90^{\circ}$ between adjacent gaps.

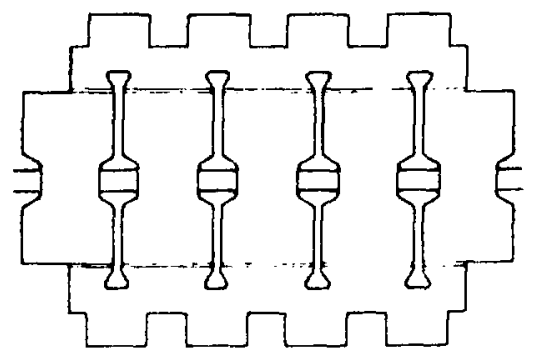

(b) Four longitudinal suppores running the length of the structure.

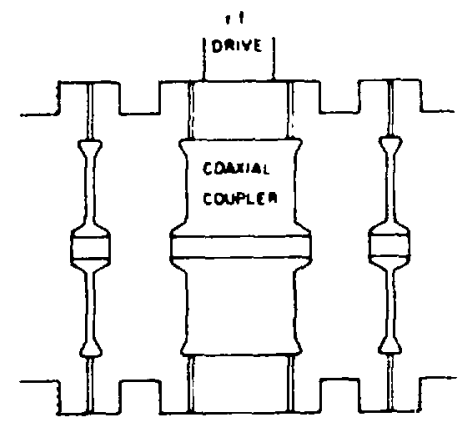

(d) Coaxial couplex, excited in TEM-like mode, employing radial supports and interconnecting adjacent accelerating sections.

Fig. 3.

Washer-support methods in DAW structure.

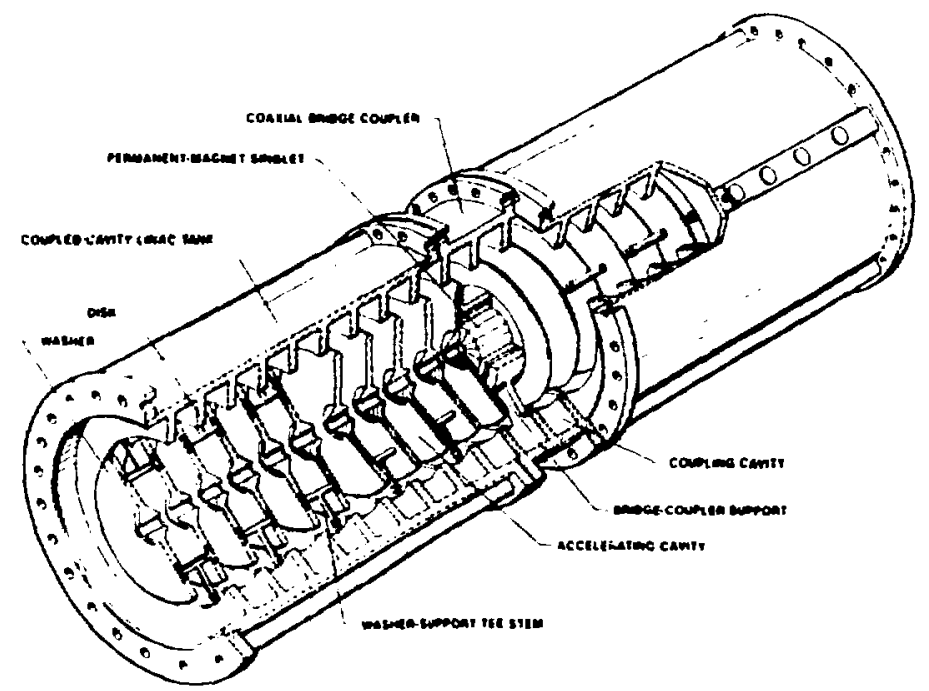

Fig. 4.

PIGMI DAW structure. 


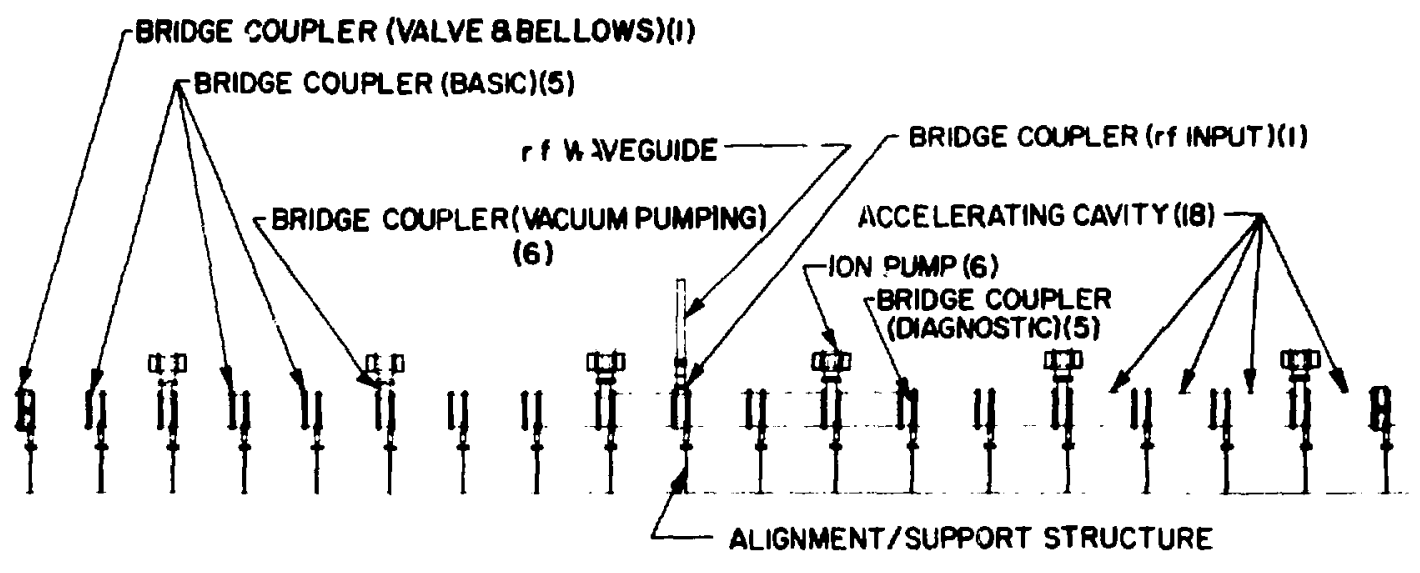

Fig. 5.

PIGMI CCL module.

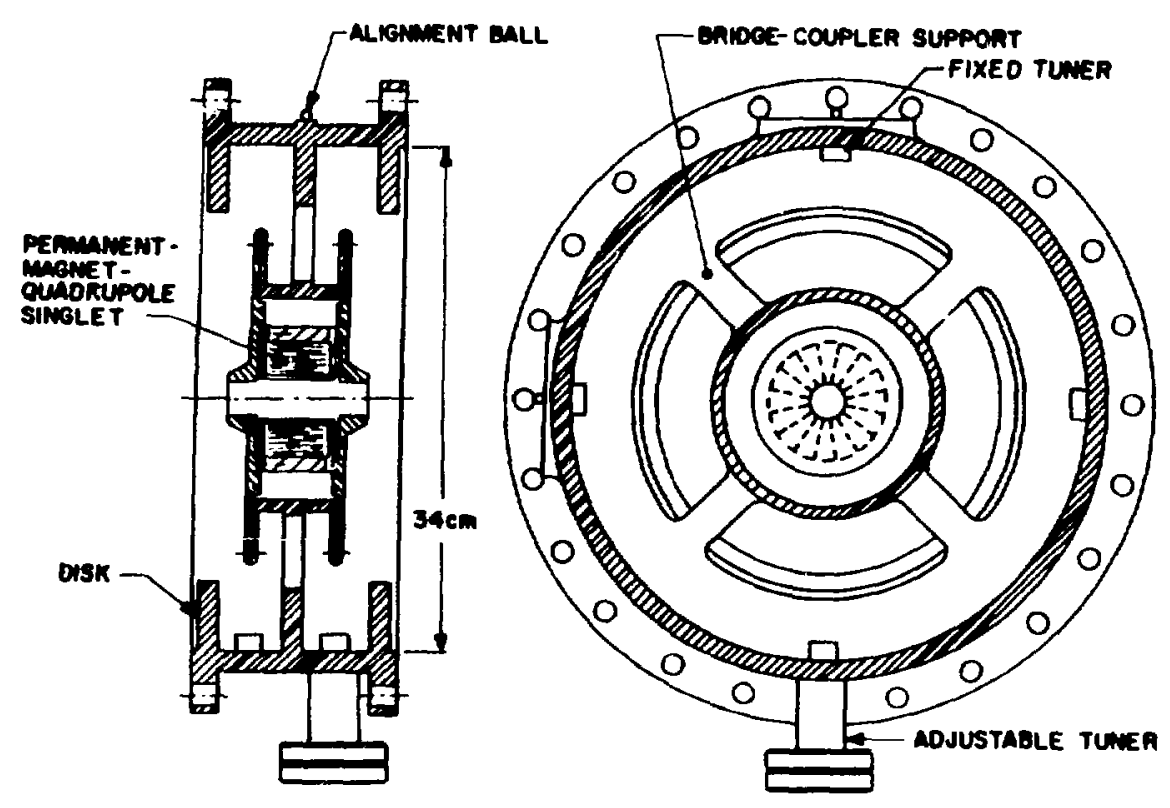

Fig. 6.

PIGMI DAW coaxial bridge coupler (basic model). 


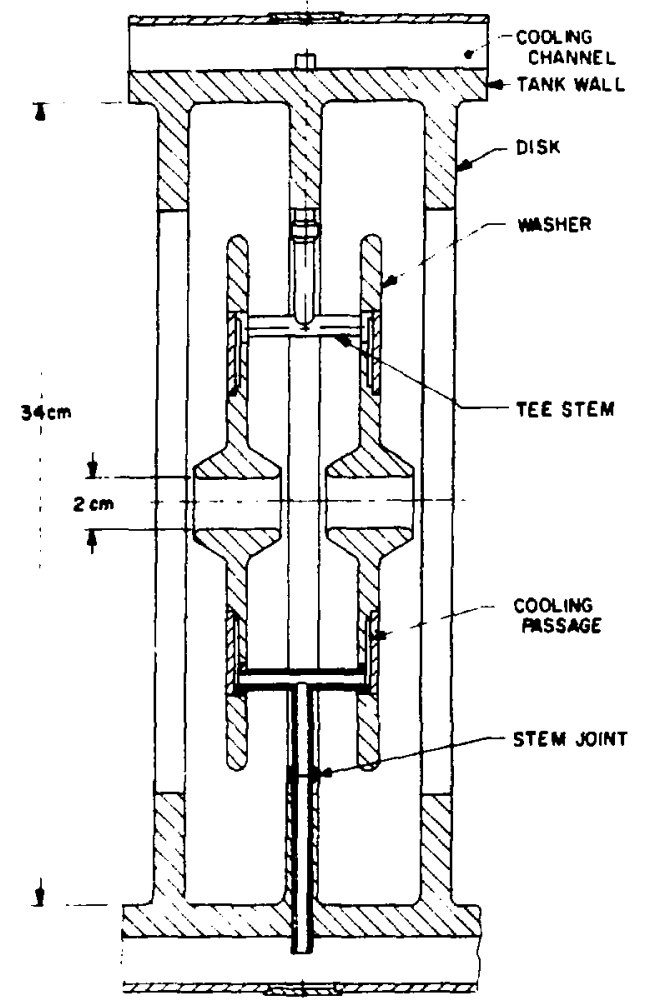

Fig. 7 .

PIGMI DAW accelerating structure.
550-uA electron beam from $100 \mathrm{keV}$ to $185 \mathrm{MeV}$, the beam is recirculated through the structure 15 times. The DAW structure also has been proposed for a variety of electron-accelerator applications.

A 324-MHz DAW structure has been proposed for the high-energy portion of the Spallation Neutron Source (SNQ) linac under study at Kernforschungszentrum Karlsruhe, West Germany." This structure would be $430 \mathrm{~m}$ long and would accelerate a 5-mA proton beam from $105 \mathrm{MeV}$ to $1100 \mathrm{MeV}$. The relatively low irequency would require a $134.8-\mathrm{cm}$ diam, with the washer diameter varying between ఒ 80 and $90 \mathrm{~cm}$. The washers would be supported in pairs by either one or two stems.

The DAW structure appears to have future applications for a variety of beams and frequency ranges. Because of the complicated geometry (from a vacuum standpoint), the vacuum calculations are not trivial. Figure 10 shows DAW cold cavities of the $2380-\mathrm{MHz}$ size made for $B=0.5,0.6,0.7$, and 0.8 . A though the cavity outside diameter remains constant, the washer outside diameter and the disk inside diameter vary with $\beta$. Compared with the side-coupled structure, the DAW structure has more surface area but is fairiy "open" for good vacuum conductance. The DAW structure vacuum calculations presented here are textbook-style analyses, tempered with experience garnered from the vacuum design of the LAMPF side-coupled structure.

\section{GENERAL IZED VACUUM EQUATIONS}

The conductance through a DAW structure may be considered by examining the limiting configurations. Conductance through the small-diameter bore hole 


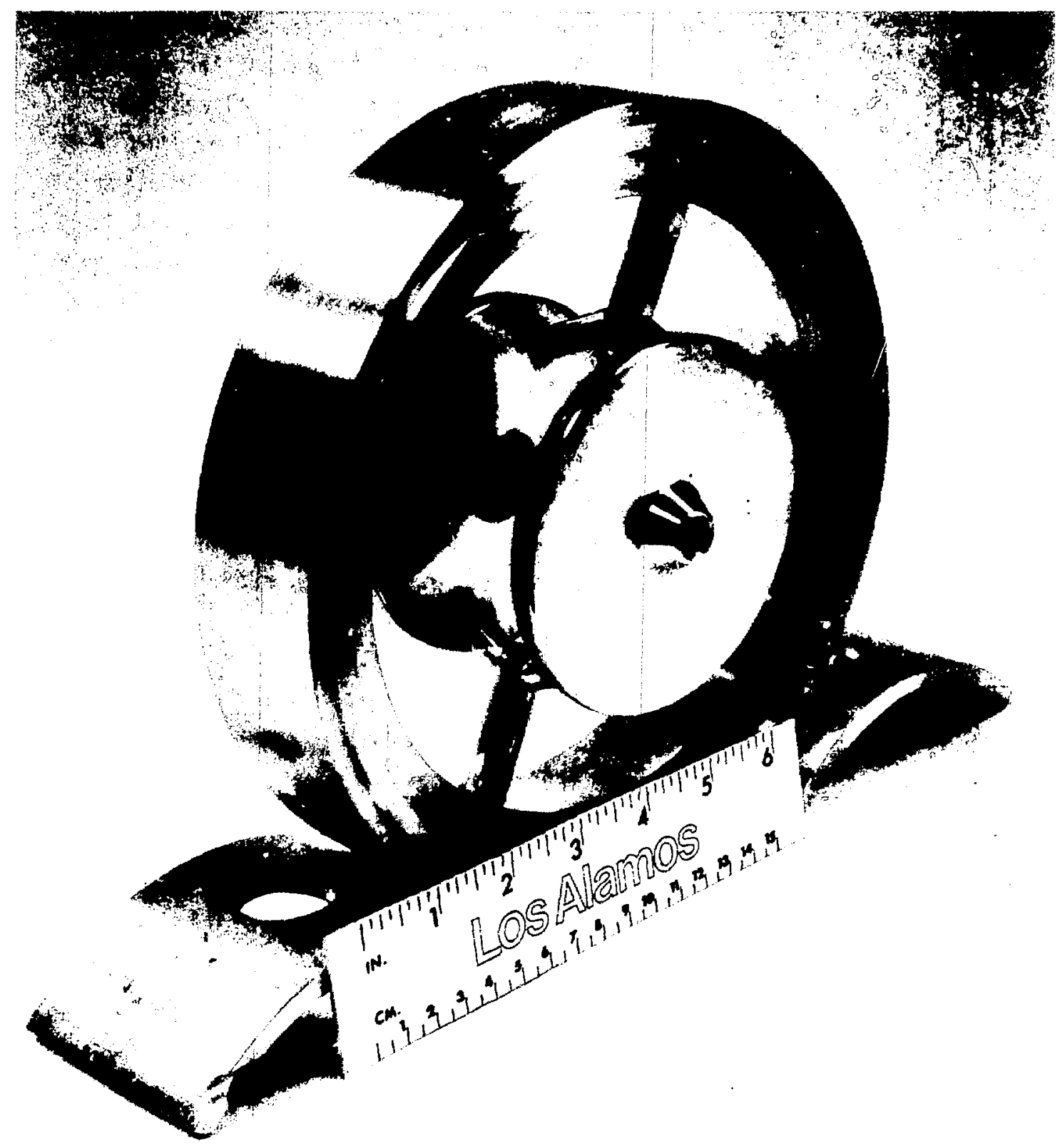

Fig. 8.

RTM DAW structure. 


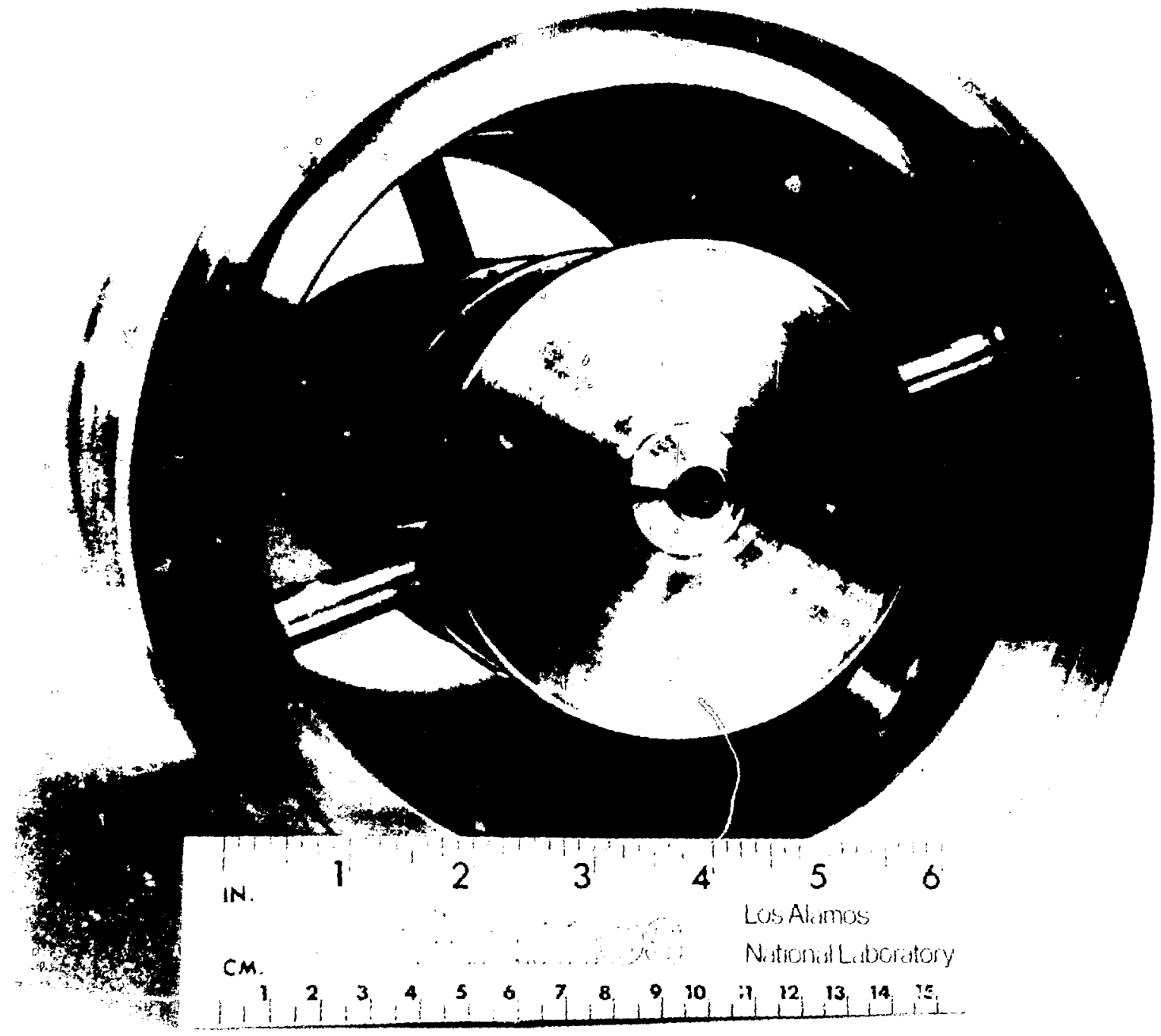

Fig. 9.

RTM DAW structure, 


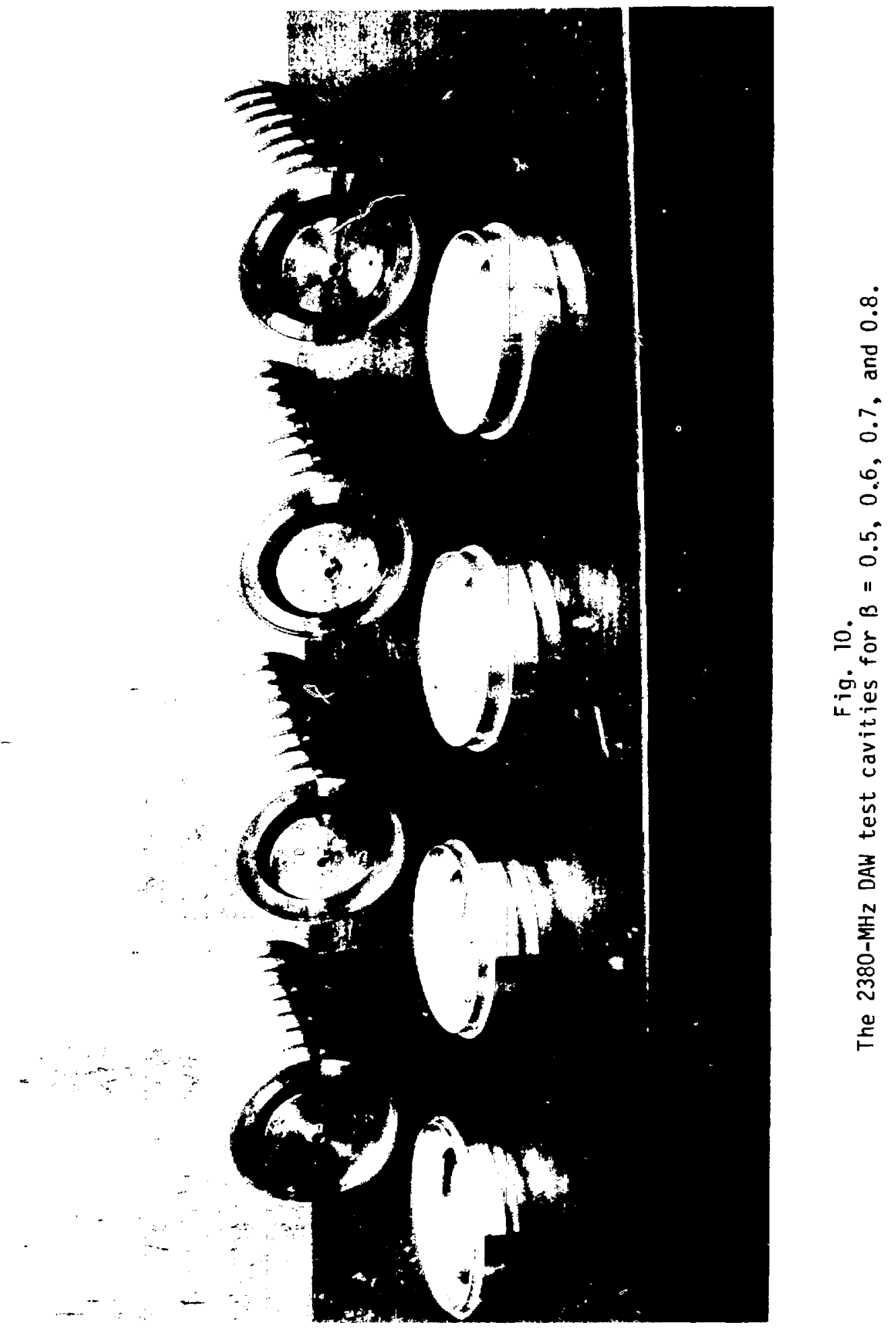


has been neglected in all cases. A lower limit for the conductance $\left(C_{L}, \ell / s\right)$ may be established by considering the conductance of an annular tube having an inside radius the same as the washer diameter $\left(D_{w}, \mathrm{~cm}\right)$, and an outside diameter equal to the disk diameter $\left(D_{d}, \mathrm{~cm}\right)$. The axial conductance of this configuration (Fig. 11) of length $L(\mathrm{~cm})$ is $^{5}$

$$
C_{L}=(12.12) \frac{\left(D_{d}^{2}-D_{w}^{2}\right)\left(D_{d}-D_{w}\right)}{L+4 / 3\left(D_{d}-D_{w}\right)} \quad \ell / \mathrm{s} .
$$

The upper limit for the conductance $\left(C_{u}, \ell / s\right)$ may be established by considering the conductance of a simple conically shaped aperture formed between the disk and washer, as shown in Fig. 12. The conductance of this configuration is

$$
c_{u}=11.6(A) \quad \ell / \mathrm{s},
$$

where $A$ is the surface area $\left(\mathrm{cm}^{2}\right)$ of a conical section of height $h(\mathrm{~cm})$,

$$
A=\pi \frac{D_{d}+D_{w}}{2}\left[h^{2}+\left(\frac{D_{d}-D_{w}}{2}\right)^{2}\right]^{1 / 2} \mathrm{~cm}^{2},
$$

$l$ is the length of a half-cell of the DAW structure, and $h=l-\left(W_{d}+W_{w}\right) / 2$. Therefore, the upper limit on conductance is

$$
c_{u}=18.2\left(D_{d}+D_{w}\right)\left[h^{2}+\left(\frac{D_{d}-D_{w}}{2}\right)^{2}\right]^{1 / 2} \ell / s .
$$

The actual value for the axial vacuum conductance of the DAW structure will be between $C_{L}$ and $C_{U}$. 


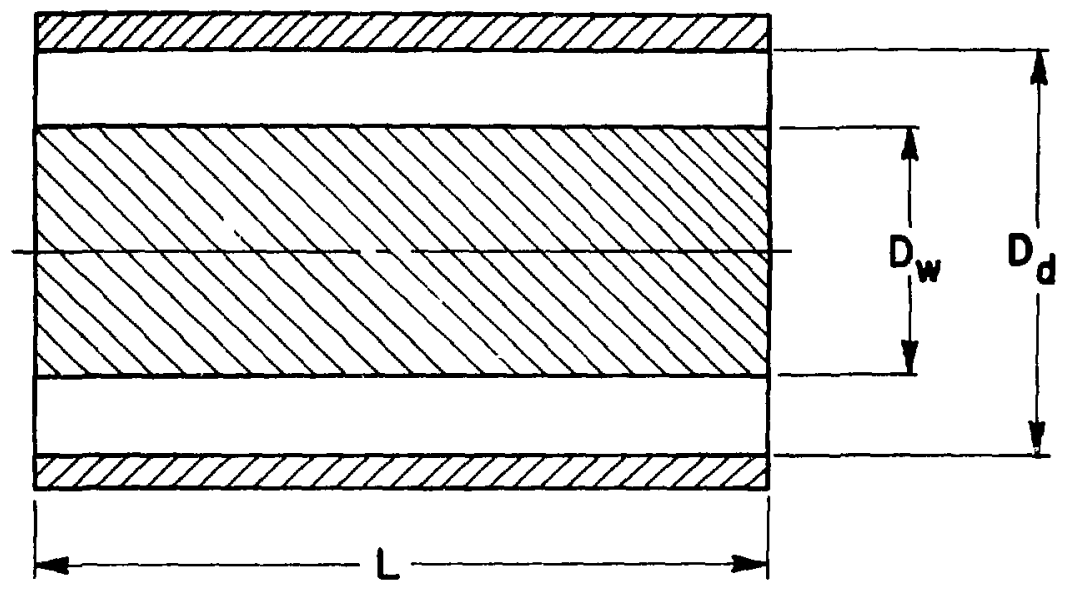

Fig. 11.

Configuration for DAW minimum conductance.

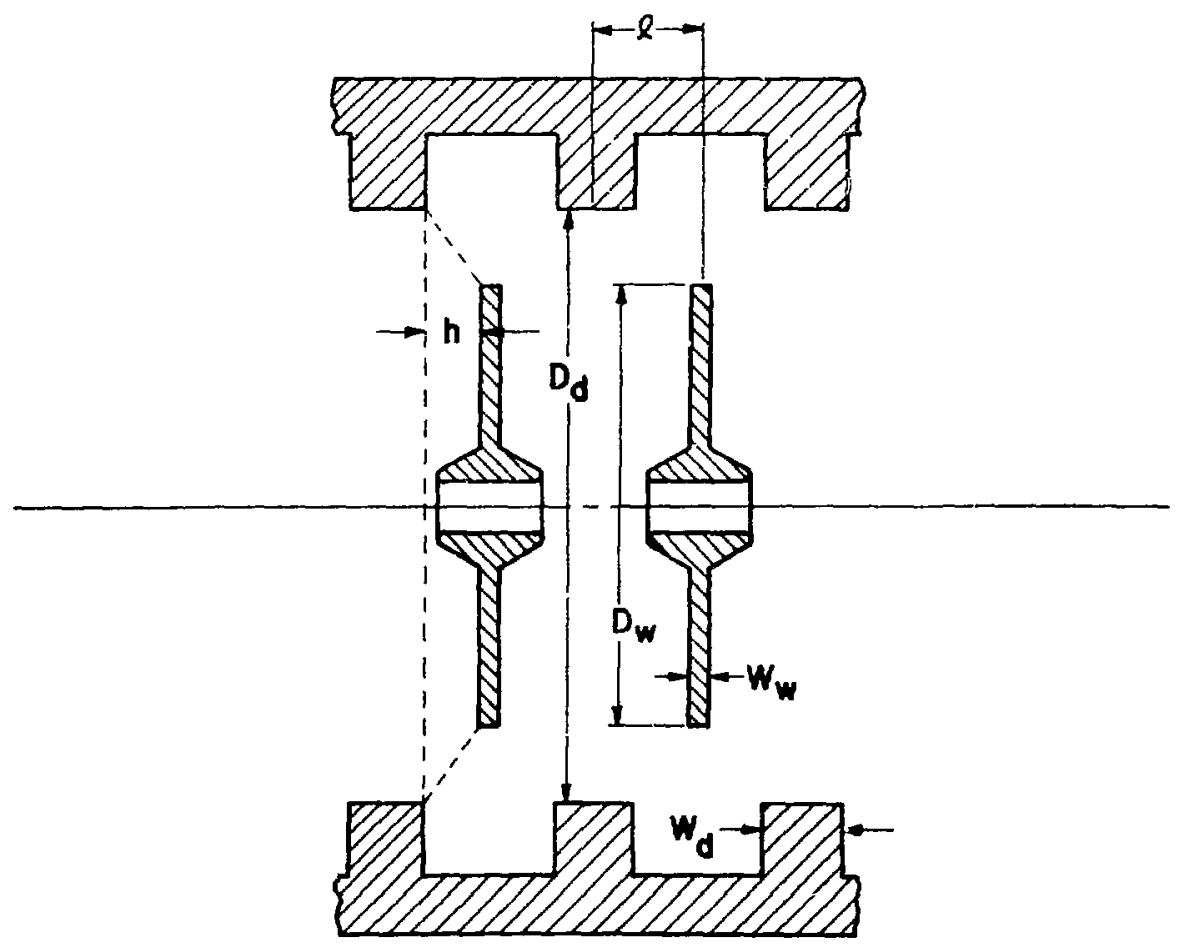

Fig. 12.

Configuration for DAW maximum conductance. 
Pumping the DAW structure typically would be through a slotted grill similar to that shown in Fig. 13. The conductance through a slot of this type $\left(C_{s}, \ell / s\right)$ is?

$$
c_{s}=30.9 \frac{a^{2} b^{2}}{(a+b) h \cdots 8 / 3(a b)} \quad \ell / s,
$$

where $\quad a=$ length of each slot $(\mathrm{cm})$,

$b=$ width of each slot $(\mathrm{cm})$, and

$h=$ wall thickness of slotted surface $(\mathrm{cm})$.

The conductance of the grill will be the summation of the conductance of each slot.

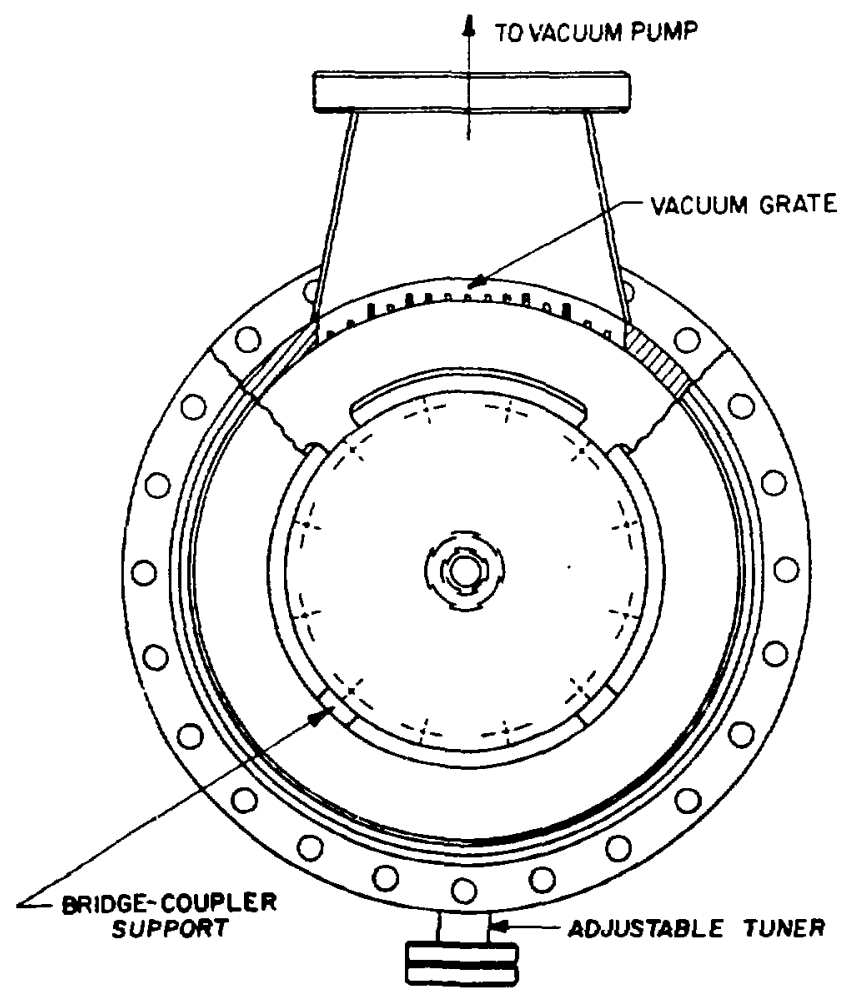

Fig. 13.

PIGMI DAW coaxial bridge coupler (vacuum-pump mode1). 
The conductance through the re:tangular vacuum box from the grill to the flange (pump throat) can be solved using Eq. (5). In this case, $a=$ width of the vacuum box $(\mathrm{cm}), b=$ length of the vacuum box $(\mathrm{cm})$, and $h=$ distance from the grill to the pump throat $(\mathrm{cm})$.

\section{SPECIFIC DESIGN EXAMPLE}

To illustrate the use of the generalized DAW vacuum equations, the vacuum requirements calculated for the PIGMI CCL (Fig. 4) are presented. This example is based on the use of ion pumps that have operating characteristics determined by data obtained from copper, copper-clad, and copper-plated materials. An ion pump is selective in respect to the speed at which it pumps various gases. Pumping-speed curves supplied by ion pump manufacturers (Fig. 14) are based on pumping pure nitrogen under idealized conditions. These pumping-speed curves cannot be applied directly to the problem of pumping the various gases that

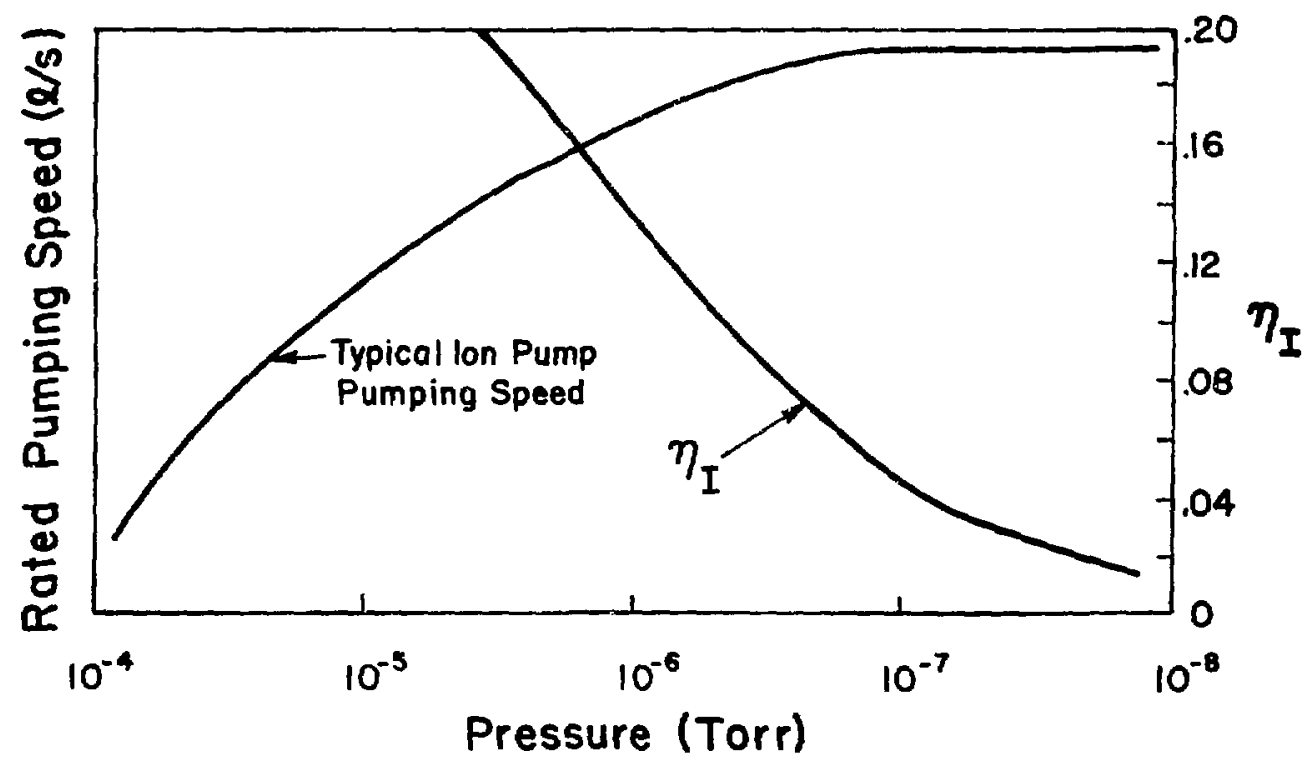

Fig. 14 .

Typical pumping curve for ion pumps/ion pump efficiency factor $\left(n_{I}=\frac{\text { measured pumping speed of copper outgas }}{\text { manufacturers pump rating for air }}\right)$. 
evolve from copper surfaces exposed to radio-frequency ( $r f$ ) currents. A curve showing the average values obtained from a number of accelerator systems is given in Fig. 14, where $n_{I}$ is the ratio of the measured speed for copper outgas divided by the manufacturers' rated pumping speed." In this example, all pump sizes stated for the linac refer to the manufacturers' rating, with the necessary considerations having been made for pumping rf-excited copper surfaces.

A CCL operating vacuum of $9 \times 10^{-7}$ torr was assumed. Vacuums in the range of $10^{-7}$ torr are necessary to achieve the required high $r f$ fields in the PIGMI CCL. Outgas values for accelerator structure materials should be based on data obtained from experience with large systems having copper surfaces and the associated stainless steel manifolding. The materials exposed to $r f$ power generaliy will experience an increase of outgas rates by a factor of 215 . The following are typical outgas rates used for accelerator vacuum analysis.

Copper

Copper (exposed to $r f$ )

Aluminum

Stainless Steel
$1 \times 10^{-10}$ torr $\cdot \ell / \mathrm{s} \cdot \mathrm{cm}^{2}$

$7 \times 10^{-9}$ torr $\cdot 2 / \mathrm{s} \cdot \mathrm{cm}^{\circ}$

$1 \times 10^{-9}$ torr $\cdot \Omega / \mathrm{s} \cdot \mathrm{cm}^{2}$

$2 \times 10^{-10}$ torr $\cdot 2 / \mathrm{s} \cdot \mathrm{cm}^{2}$

These values are for materials that have been mechanically and solvent cleaned but that have not had any vacuum-degas treatment. Values are for materials not exposed to $\mathrm{rf}$, unless specifically stated. The calculations for the PIGMI CCL were based on a typical cell of the following dimensions:

$$
\begin{aligned}
& D_{c}=33.2 \mathrm{~cm}, \\
& D_{d}=25.4 \mathrm{~cm}, \\
& D_{w}=21.0 \mathrm{~cm}, \text { and } \\
& \ell=6.6 \mathrm{~cm},
\end{aligned}
$$

where $D_{C}$ is the outside diameter of the cavity.

A module for vacuum calculations consisted of an accelerating tank (of 11 cells) and a bridge coupler (of equivalent cell dimension and constituting two cells). Only the bridge coupler presented some minor virtual-leak considerations. First, the interior surface area of the cavity was calculated. Each 
disk has a $780-\mathrm{cm}^{2}$ surface area, each washer an $813-\mathrm{cm}^{2}$ surface area; the wall section between each disk has a $563-\mathrm{cm}^{2}$ surface area, and the washer support stems have a $101-\mathrm{cm}^{2}$ surface area. Therefore, the total surface area per $13.2-\mathrm{cm}-10 \mathrm{ng}$ double cell is $4413 \mathrm{~cm}^{2}$. The outgas $\left(S_{\text {og }}\right)$ per double cell is

$$
S_{o g}=\frac{\left(10^{-9} \text { torr }-\ell \mathrm{s}-\mathrm{cm}^{2}\right)\left(4.413 \times 10^{3} \mathrm{~cm}^{2}\right)}{9 \times 10^{-7} \text { torr }}=4.9 \mathrm{l} / \mathrm{s} .
$$

Each vacuum module has 6.5 double cells. The outgas from the internal parts of the bridge coupler was calculated to be $0.3 \mathrm{l} / \mathrm{s}$; therefore, the outgas from each vacuum module totaled $32.1 \mathrm{\ell} / \mathrm{s}$. The required pump size $\left(P_{R}\right)$ was calculated by using the operating vacuum of $9 \times 10^{-7}$ torr. The curve on Fig. 14 was useci to find the ion pump efficiency $\left(\eta_{I}\right)$, which was 20.13 ; therefore,

$$
P_{R}=\frac{32.1 \ell / \mathrm{s}}{0.13}=247 \mathrm{l} / \mathrm{s}
$$

From this calculation, a $250-\ell / \mathrm{s}$ pump would be required to pump each accelerating tank and bridge coupler. Because this requirement seemed larger than anticipated, a comparison was made with LAMPF's 805-MHz side-coupled structure, for which considerable design and operating information is avail-

\begin{tabular}{|c|c|c|}
\hline Cell length & & $9.5 \mathrm{~cm}$ \\
\hline Cell diameter & & $12.8 \mathrm{cin}$ \\
\hline Operating vact & & $10^{-6}$ torr \\
\hline Module No. 8: & Cells/tank & 34 \\
\hline & Tanks & 4 \\
\hline & $\mathrm{S}_{\mathrm{og}}$ & $320 \ell / \mathrm{s}$ \\
\hline & Pumping installed & $1800 \ell / \mathrm{s}$ \\
\hline & Module length & $12.95 \mathrm{~m}$ \\
\hline
\end{tabular}
able. The applicable data for the LAMPF structure are listed below. 
Using the same $n_{I}$ as used for PIGMI, the required pumping per module would be

$$
P_{R}=\frac{320 \ell / \mathrm{s}}{0.13}=2461 \ell / \mathrm{s}
$$

The PIGMI CCL would have a factor of 1.68 larger diameter than the LAMPF structure; therefore, the equivalent pumping per unit length for a PIGMI-sized sidecoupled structure operating at $10^{-6}$ torr would be

$$
P_{R} / L=\left(\frac{2461 Q / \mathrm{s}}{12.95 \mathrm{~m}}\right)(1.68)=319 \mathrm{Q} / \mathrm{s}-\mathrm{m}
$$

If the vacuum in the PIGMI CCL were $10^{-6}$ torr (versus the $9 \times 10^{-7}$ torr previously specified), the $S_{\text {og }}$ would be $28.9 \ell . / \mathrm{s}$, and the $P_{R}$ would be $222 \ell / \mathrm{s}$. The module length is $6.6 \mathrm{~cm} / \mathrm{cell} \times 13 \mathrm{cells}=86 \mathrm{~cm}$. The pumping per unit length for a PIGMI CCL st:-ucture operating at $10^{-6}$ torr would be

$$
P_{R} / L=\frac{222 \ell . / \mathrm{s}}{0.86 \mathrm{~m}}=258 \text { l. } / \mathrm{s}-\mathrm{m} .
$$

Therefore, this calculation showed that the pumping required per unit length for equivalent side-coupled and DAW structures agrees to within $20 \%$.

Another method used to check the accuracy of the PIGMI CCL calculations was to compare the installed pumping $\left(P_{I}\right)$ per unit length. For LAMPF, using the 1.68 physical scaling factor,

$$
P_{I} / L=\left(\frac{1800 \ell . / \mathrm{s}}{12.95 \mathrm{~m}}\right)(1.68)=254 \mathrm{\ell} / \mathrm{s}
$$

For the PIGMI CCL, using one $250-l / \mathrm{s}$ pump per $86-\mathrm{cm}-10 n g$ module, the equivalent installed pumping per unit length would be

$$
P_{I} / L=\frac{250 \ell / s}{0.86 \mathrm{~m}}=290 \ell / \mathrm{s}-\mathrm{m}
$$


This comparison showed that the pumping agrees to within 13\%; therefore, the PIGMI CCL requirement of $2250 \mathrm{Q} / \mathrm{s}$ pumping per accelerating tank and bridge coupler is reasonable, compared to LAMPF.

Conductance through the structure was considered because of the configuration and the pump locations on the bridge couplers. The vacuum conductance through the structure was calculated using Eqs. (1) and (4). The axial vacuum conductance had a maximum value of $1345 \mathrm{l} / \mathrm{s}$ and a minimum value of $87 \mathrm{l} / \mathrm{s}$. These conductance valjes indicated that tirree (or possibly four) vacuum modules could be pumped in series without a significant loss in pumping speed.

The conductance of the vacuum grill in the bridge coupler and the vacuum box was calculated using Eq. (5). A grill containing twenty l-cm-wide slots, each $4 \mathrm{~cm}$ long and $0.6 \mathrm{~cm}$ thick, had an $1155-\ell / \mathrm{s}$ conductance. The vacuum box, $9.4 \mathrm{~cm}$ long, $10.5 \mathrm{~cm}$ high and with an average width of $216.8 \mathrm{~cm}$, had an $1125-l / s$ conductance. These conductances are well matched and allow the pumping of four vacuum modules per pump. The calculated pump size was $1000 \mathrm{l} / \mathrm{s}$; however, the recommended pump size is $500 \mathrm{l} / \mathrm{s}$, considering that outgas rates will drop once the system is under vacuum and $r f$ power and allowing for a nominal clean-up period under these conditions. As shown in Fig. 5, the PIGMI CCL is designed to have one ion pump per three vacuum modules.

A concern with the arrangement shown in Fig. 5 was the effect on the vacuum if there were a pump failure. There appeared to be no conductance problems through the structure. The worst condition would be the loss of the first or last pump in the CCL, which would require flow through six vacuum niodules to reach an operating pump. Loss at any other pump would result in flow through four modules, and the pressure rise in this case would probably be a factor of 23 to 4 . Loss of two adjacent pumps would be a much more serious matter and might result in a vacuum too poor to allow continued operation.

\section{CONCLUSION}

The DAW structure has very good vacuum axial conductance. As DAW structures are built for future accelerators, empirical equations will replace those used for the present estimates. The DAW structure is deceptive in that it contains relatively large surface area compared with a side-coupled structure; 
however, because of the DAW structure's high axial conductance, the consequences of a single pump outage are less than in the side-coupled structure and not as likely to affect continued accelerator operation.

\section{REFERENCES}

1. S. 0. Schriber, "High-Beta Linac Structures," Proc. 10th Linear Accelerator Conf., Mortauk, New York, September 10-14, 1979, Brookhaven National Laboratory report BNL -51134 , p. 164 (1980).

2. L. D. Hansborough, Compiler, "PIGMI: A Design Report for a Pion Generator for Medical Irradiations," Los Alamos National Laboratory $\overline{r e p o r} \overline{\mathrm{t}}$ LA-8880

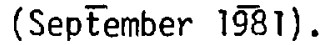

3. S. Penner, R. I. Cutler, P. H. Debenham, E. R. Lindstrom, D. L. Mohr, M. A. D. Wilson, N. R. Yoder, L. M. Young, T. J. Boyd, E. A. Knapp, R. E. Martin, J. M. Potter, C. M. Schrieider, D. A. Swenson, and P. J. Tallerico, "The NBS-LASL CW Microtron," Proc. 6th Conference on the Application of Accelerators in Research and Industry, Denton, Texas, November 3-5, 1980, IEEE Trans. Nuc 1. Sci. 28, p. 1526 (1981).

4. J. E. Vetter, Ed., "The Basic Concept of the SNQ Linear Accelerator," Institute für Kernphysik, Kernforschungszetrum Karlsruhe Gmbtt report KfK-3180B (June 1981).

5. C. M. Van Atta, Vacuum Science and Engineering (McGraw-Hill Book Company, New York, 1965), p. 62.

6. C. M. Van Atta, Vacuum Science and Engineering (McGraw-Hill Book Company, New York, 1965), p. 60.

7. C. M. Van Atta, Vacuum Science and Engineering (McGraw-Hill Book Company, New York, 1965), p. 61.

8. H. G. Worstell, "LAMPF 201-MHz Vacuum System," Los Alamos Scientific Laboratory, Accelerator Technology Division, Group MP-3 memorandum No. MP-3/HGW-6 (January 13, 1967). 